\title{
Evaluation of a Community-Scale Drinking Water Treatment System
}

\author{
Keah-Ying Lim \\ Senior, Department of Civil Engineering \\ University of Mississippi \\ University, MS 38677 \\ keahying@gmail.com \\ Shannon Wilson \\ Graduate Student, Department of Civil Engineering \\ University of Mississippi \\ University, MS 38677 \\ shannonwilson86@gmail.com \\ Emily Woolsey \\ Senior, Department of Geology and Geological Engineering \\ University of Mississippi \\ University, MS 38677 \\ eewoolz@gmail.com \\ Cristiane Q. Surbeck \\ Assistant Professor, Department of Civil Engineering \\ University of Mississippi \\ University, MS 38677 \\ csurbeck@olemiss.edu
}

\begin{abstract}
This paper presents the results of a community-scale drinking water treatment system assessment by University of Mississippi School of Engineering students and the organization Living Waters for the World (LWW). Communities facing a severe lack of sustainable and clean drinking water use LWW microfiltration, ozone water treatment, ultraviolet, and chlorination systems worldwide. Students worked on two projects: (1) evaluation of the ozonation system by measuring several water quality parameters, and (2) creation of a chlorine concentration table based on strength and volume of bleach added to a batch of water. The students' assessment determined that the LWW ozone disinfection and microfiltration system effectively treats water by removing and inactivating bacteria that could cause adverse health effects in humans. When developing the chlorination table, students considered typical units of measurement and tools available in disadvantaged communities. Students learned and performed water quality testing while considering technical and social implications of the treatment systems.
\end{abstract}

Index Terms - drinking water treatment, ozone, chlorination, disinfection, service learning 


\section{INTRODUCTION}

\section{The World Water Crisis and Living Waters for the World}

Nearly one billion people in the world have no access to clean water, and nearly three million people die each year from water-borne illnesses. To address these issues, among other problems facing the developing world, the United Nations has established a set of Millennium Development Goals. One of these goals is to halve the number of people without access to a clean and safe water source by 2015. Improvements to water sources will have a direct effect on the health of children and expecting mothers, increase crop yields and decrease hunger, and improve the quality and sustainability of the environment. ${ }^{i}$

In response to the statistics on the lack of availability of clean water, Minister Wil Howie developed Living Waters for the World (LWW), an organization aimed at providing sustainable clean water in underdeveloped regions around the world. LWW emphasizes a "train the trainer" model in which team members from the United States attend "Clean Water U," a series of classes in which they learn how to teach community members in an underdeveloped region hygiene practices and how to install and operate water treatment systems. Rather than simply providing clean water to underdeveloped communities, LWW partners with teams to train them how to train community members on the use of clean water systems. The team members from the U.S. then go to the underdeveloped regions and teach community members how to install and operate the water treatment systems.

Since its development in the early 1990s, LWW partners have taught community members in underdeveloped regions to install and operate over 300 clean water systems in 24 countries around the world. The organization also develops water treatment systems for in-home use in the Appalachian region of the United States. LWW partners have been involved in the installation of clean water systems in Haiti, Mexico, Kenya, Laos, Thailand, and other developing countries.

\section{Service Learning in Water and Sanitation Engineering}

In an effort to expose university students to the world crisis involving clean water and healthy sanitation practices, a one-semester course titled Service Learning in Water and Sanitation Engineering has been offered to University of Mississippi (UM) seniors and graduate students. This course has become a unique and synergistic partnership between a university and a nongovernmental organization. Lessons learned by the students in the first offering of this course are presented in this paper.

The first offering of the course combined traditional lecture-style learning with hands-on experience both in field and in laboratory settings. In the classroom, students learned about water disinfection theory, sanitation and wastewater treatment practices, and pump and pipe flow theory. Students were also trained on how to install and operate the ozone disinfection system at Clean Water U. Two technical projects completed in class are described in this paper along with their social implications.

In the first project, students developed an experimental protocol to analyze the effectiveness and efficiency of the ozone disinfection system, and completed the experiments in a combination of field and laboratory work. In the laboratory, students followed U.S. Environmental Protection Agency (EPA)-approved analytical methods for the determination of coliform bacteria concentrations in water passing through the ozone disinfection system. In the second project, students conducted chlorination experiments and applied mathematical equations 
to develop a user-friendly table that allows system operators to quickly estimate the concentration of chlorine in a batch of water. The students described the two projects in a final technical report and presented the information to the director and members of LWW.

The course is now in its second offering and will continue to be offered to UM senior and graduate students in future years. As an ongoing effort to analyze and improve LWW's treatment systems, the findings of the work conducted in one semester are utilized as background for projects to be conducted during the following offering of the course.

\section{Background and Project Overview}

The following sections describe the technical content learned by the students and the work performed with the aim of answering technical questions posed by LWW.

\section{Background on Water Quality Parameters}

Water quality is evaluated by testing parameters. In the United States, the EPA sets standards for drinking water quality. These standards are known as maximum contaminant levels (MCLs). MCLs dictate the maximum level of a contaminant that can legally exist in water meant for human consumption.

As part of the first project, in the assessment of the ozone disinfection system, coliform bacteria concentrations were evaluated because they indicate presence of pathogens. Coliform bacteria and pathogens may originate from the same source, but coliform bacteria are much easier to detect. Pathogens are harmful, disease-causing microorganisms; common waterborne pathogens can cause typhoid fever, cholera, and bacillary dysentery. Escherichia coli (E. coli), a subgroup of coliform bacteria, may include pathogenic strains such as E. coli O157:H7, which causes severe adverse health effects in humans. In the U.S., the EPA enforces a MCL of zero for the fecal coliform E.coli in drinking water. ${ }^{\text {ii }}$

Other water quality parameters measured by the students, but not subject to MCLs, in the analysis of the ozonation disinfection system developed by LWW included dissolved oxygen (DO), and oxidation-reduction potential (ORP). Ozone concentrations were also collected to better understand the mixing of ozone with water over time and distance along the plug flow reactor (30-feet of 1-inch pipe assembled in several 3-foot vertical sections connected by 90 degree elbows) in the treatment system.

DO is a frequently assessed water quality parameter. Low DO concentrations in water suggest ecosystem imbalances, such as pollution, as oxygen supports healthy aquatic life. For example, excessive organic loads in water result in lower levels of DO because organics consume the oxygen. ${ }^{\text {ii }}$

ORP is a measure of the tendency of a solution to gain or lose electrons. Higher ORP readings correspond with a greater tendency of the solution to gain electrons. Ozone injection into water increases its oxidation potential. Therefore, typically ORP increases as more ozone is injected into the water.

\section{Background on Disinfection by Ozonation}

Ozone $\left(\mathrm{O}_{3}\right)$ is an oxidizing gas used to disinfect water by inactivating microorganisms. Ozone is formed when three atoms of oxygen bind together. Ozone will oxidize, or gain electrons, from other substances. In doing so, it will kill bacteria that exist in water. ${ }^{i}$ Ozone-treated water has a more pleasant taste than chlorinated water. The disadvantages of using ozone in large-scale 
treatment plants are its higher cost and inability to produce a long-lasting disinfection residual. However, in LWW's community-scale drinking water treatment system (Figure 1), when the water is properly captured in a prepared bottle that is immediately sealed, ozone residual may be enough to sufficiently disinfect the water.

The ozonation disinfection system used by LWW to kill bacteria in drinking water employs a unique system of passing the water through an ozonator and plug flow reactor twice. This is called a two-pass system. On the first pass through the ozonation system, raw water passes through three filters (Figure 1, components 1, 4 and 6) to remove particulate matter and microorganisms greater than $0.5 \mu \mathrm{m}$ in size. Then, the water passes through a venturi connected to an ozonator (Figure 1, components 9 and 8). A venturi contains a tube that provides suction from the ozonator, thereby injecting ozone into the passing water. The ozonated water travels through a plug flow reactor (Figure 1, component 10), where the ozone oxidizes and kills bacteria present in the water. On the second pass through the ozonation system, water bypasses the filters and travels directly to the venturi connected to the ozonator and through the plug flow reactor. After the second pass, the water is disinfected and ready for bottling and distribution (Figure 1, component 11). This unique two-pass system is designed to permit enough contact time between ozone and water to deactivate pathogens before the water is bottled and distributed.

Each step in the disinfection by ozonation system is designed to remove or treat a specific aspect of the raw water. The filtration step permits the physical separation of microorganisms from the water by passing the raw water through a series of filters with pore sizes smaller than most microorganisms. Three separate filters are used in the ozone system. Water from the raw water tank first passes through the $50-\mu \mathrm{m}$ sediment or trash filter, which removes dirt, sand, and algae. Water is then pumped through a $5-\mu \mathrm{m}$ microfilter to remove microorganisms growing together in multi-celled colonies. The final $0.5-\mu \mathrm{m}$ activated carbon microfilter is designed to remove most single-celled microorganisms. The filtration design concept is to remove the largest particles first and filter out smaller ones with each subsequent filter.

The ozonation step is designed to deactivate bacterial pathogens that are likely to exist in raw surface water. The LWW ozonation system uses the Prozone PZ2-4 ozonator and the Prozone V3 Dynamic Injector attached to a venturi. Ozone is generated in the system by passing air, which contains oxygen, under UV light, which maintains a high voltage potential. As oxygen flows through the electrodes in the cell, ozone is produced and immediately introduced into the water column. The average ozone production rate of the PZ2-4 ozonator is 2 grams per hour. Ozone is minimally soluble in water and therefore must be injected into the water stream through the vacuum created by the flow of water through the venturi. Water must pass through a total length of at least 30 feet of vertical polyvinyl chloride (PVC plastic) piping after the venturi to ensure adequate contact time between the ozone and water. The transfer, mixing, and contact time between the ozone and water are the most important factors in the ozone disinfection process. $^{\text {iii }}$

This water treatment system and the manner in which it is owned and operated by disadvantaged communities around the world have been both appropriate and sustainable. Other than the ozonator, parts for these treatment systems are off-the-shelf, inexpensive, and found in most countries. The systems are safe to operate. LWW educates mission groups to interact with the in-country operating partners over several trips, making the relationships long-term. The mission groups encourage the operating partners to own the systems with pride and operate them as micro-businesses, rendering these water treatment systems sustainable for many years. 


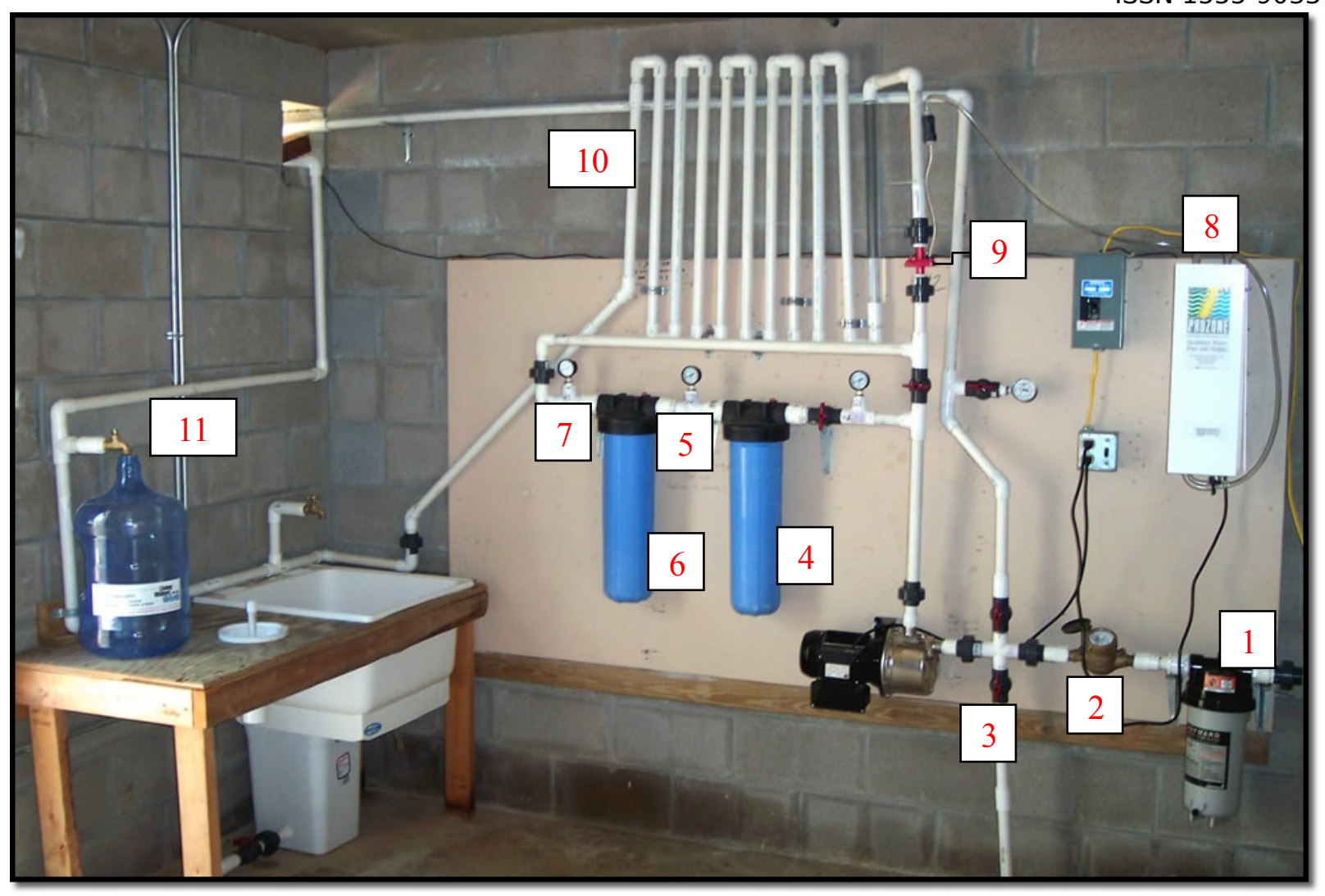

FIGURE 1

The OZONE DISINFECTION SYSTEM USED BY LWW EMPLOYS A UNIQUE TWO-PASS SYSTEM TO TREAT WATER. THe COMPONENTS OF THE

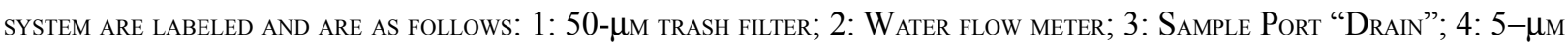
filter; 5: Sample port G2; 6: 0.5- $\mu$ m filter; 7: Sample port G3; 8: Ozonator; 9: Venturi connected to ozonator; 10: Plug flow Reactor. 11: Bottling station.

\section{Background on Chlorine Disinfection}

Chlorine disinfection is a method used to remove pathogens from drinking water. It is typically used in conjunction with other treatment methods in order to complement other elements of drinking water treatment. ${ }^{\text {iii }}$ LWW does not use chlorine in the ozone-based treatment systems, but uses it instead for residual disinfection in its UV-disinfection systems and pre-treatment of raw water. LWW has found that in many cultures, excess residual chlorine causes an unpleasant taste and odor in the drinking water that many people will not drink. This makes an appropriate, but not excessive, level of chlorine disinfection important.

To reduce the odor and taste chlorine imparts on the water, the use of chlorine for disinfection can be optimized by adjusting the dosage. Chlorine is used not only to provide a residual concentration for disinfection after bottling, but also to decontaminate other disinfection systems (such as the ozonation disinfection system).

Decontamination entails conveying water with a high chlorine concentration through the system to remove bacteria. According to the LWW's Clean Water Systems Handbook - Standard System, Vol. 1, the recommended chlorine dosage for disinfection varies depending on its application. For example, the recommended chlorine dosage for decontaminating a disinfection 
system ranges from 50 to $200 \mathrm{mg} / \mathrm{L}$, whereas the chlorine dosage for providing residual disinfection for clean bottled water is 0.2 to $0.6 \mathrm{mg} / \mathrm{L}^{\text {iv }}$

Achieving the recommended chlorine dosage given its intended use is critical. Operators of the disinfection system may have little to no technical background. In order to support that a proper concentration of chlorine is used, a simple mathematical analytical model was developed in the form of a table to guide the user on how to make a chlorine solution with the desired chlorine dosage and verify its accuracy by carrying out a simple laboratory test. This model is depicted in the section below.

\section{Evaluation of the Ozonation Disinfection System}

In order to assess the water treatment system, the UM Service Learning in Water and Sanitation Engineering class first had to learn the configuration of the system and how to operate it. Handson operating experience, along with help from LWW members, allowed students to learn the path of the water through the treatment system, as depicted in the Disinfection by Ozonation section. Isolating each component and learning its individual purpose allowed students to understand the system as a whole.

The objective of the students' assessment of the ozonation system was to measure water quality parameters at system component inlets and outlets to understand how water quality improves with each step along the treatment process. The water quality data were then used to assess the system for effectiveness and efficiency. To do this, water samples were collected from locations in the system while the ozonator was in operation, a procedure not previously completed by LWW. Collecting these samples while the ozonator was in operation was achieved by installing five sample ports along the plug flow reactor and utilizing the existing ports located after each filter. Figure 2 is a schematic of the locations in the plug flow reactor where the students installed sample ports.

The first sample port was placed downstream of the venturi and the fifth sample port was placed at the end of the plug flow reactor. The other three sample ports were installed along the plug flow reactor at locations in the middle, top, and bottom of separate vertical pipes. The sampling protocol included use of existing hardware by collecting water samples from existing gauge ports and drains. 


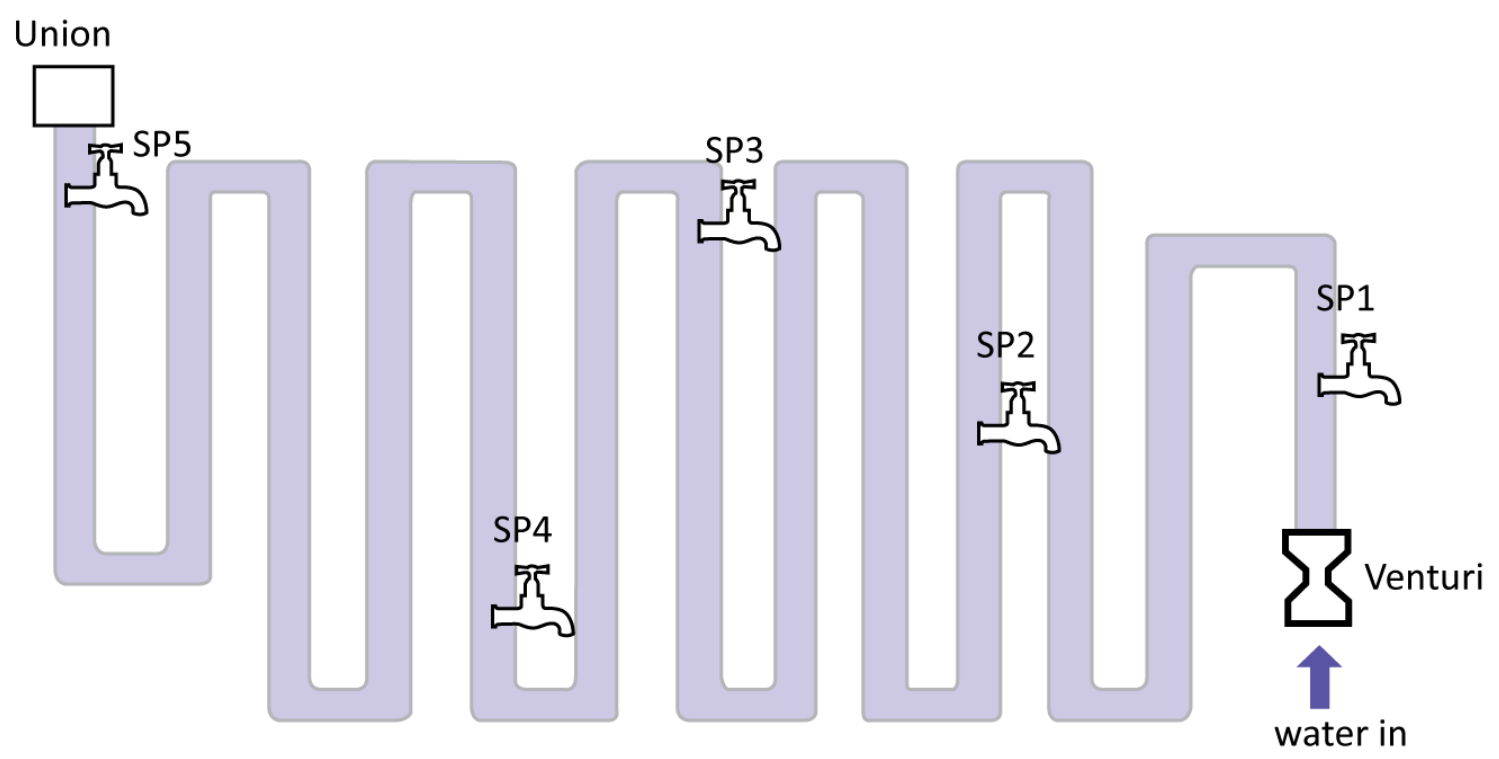

FIGURE 2

A SCHEMATIC OF THE LOCATIONS OF SAMPLE PORTS (SP1 THROUGH SP5) ON THE PLUG FLOW REACtOR.

Water quality parameters were analyzed at the treatment facility in both passes through the system. Water samples were analyzed for total coliform, E. coli, DO, ozone, and ORP. They were collected after the $50-\mu \mathrm{m}, 5-\mu \mathrm{m}$, and $0.5-\mu \mathrm{m}$ filters and at the five sample ports along the plug flow reactor. Samples from the raw water tank and a drain representing the inlet to the system were collected to identify background levels. Multiple trials of each pass were carried out to obtain average results.

All sample analyses were conducted according to commonly-accepted methods. The bacteria analysis was completed using a defined-substrate method (IDEXX Laboratories, Inc. Westbrook, ME, U.S.A.). Ozone and DO tests were conducted on-site using a CHEMetrics V2000 Multi-Analyte photometers (Calverton, VA). ORP was measured on-site in millivolts with a digital meter and probe.

Flow rate was measured on the first pass with the water meter by counting the number of gallons that passed through the system per minute (Figure 1, component 2). Water does not flow through the meter on the second pass, so the flow rate was estimated by measuring the time required to fill a 5 -gallon bucket.

Pressure readings were taken from pressure gauges.

\section{Development of a Chlorination Analytical Model}

A chlorine dosage table was created in Microsoft Excel to provide a quick reference of how much bleach is needed to yield a certain chlorine concentration in water. Commercial bleach contains a certain percentage of chlorine available for disinfection; the bleach is added to water and serves as the source of chlorine for disinfection. The percent of available chlorine will vary 
depending on the type of bleach (powder or liquid bleach), the manufacturer, and the region where the bleach is manufactured. The bleach that is commercially available in the United States may be vastly different from the bleach that is commercially available in other parts of the world. Because these systems are installed in a variety of global regions, it was important to create a table that took into account a wide range of available chlorine percentages.

The table was prepared analytically to show the amount of bleach needed to achieve a given chlorine concentration $(\mathrm{mg} / \mathrm{L})$ in a certain volume of water as a function of the percent available chlorine in the bleach. As such, the key information needed for the calculations is the percent available chlorine in the bleach, density of bleach and the volume of water. In the U.S., standard Clorox ${ }^{\circledR}$ bleach yields $5.7 \%$ available chlorine according to the manufacturer's label. Using standard Clorox ${ }^{\circledR}$ bleach, students measured the mass and volume of Clorox ${ }^{\circledR}$ in the laboratory and determined the density of bleach to be $1088 \mathrm{mg} / \mathrm{mL}$. Using this information, the mass of free chlorine and chlorine dosage in solution and can be calculated using the following equations.

\section{Chlorine Dosage $(\mathrm{mg} / \mathrm{L})=$ Mass of Chlorine $(\mathrm{mg}) /$ Volume of mixture $(L)$}

Mass of Chlorine $(\mathrm{mg})=\%$ available chlorine $\mathrm{x}$ Vol. of Bleach added $(\mathrm{mL}) \mathrm{x}$ Density of Bleach $\left(\frac{\mathrm{mg}}{\mathrm{mL}}\right)$

The equations above were converted into an Excel formula. The fundamental parameters, the volume of water and the percent available chlorine, were set as input parameters in the table. Users could then enter a given volume of water and percent available chlorine usually found on the label of a bottle of bleach. The Excel spreadsheet then generates the resulting concentration of chlorine in water for a range of added volumes of bleach.

\section{RESULTS}

\section{Evaluation of the Ozone Disinfection System}

Samples were collected from the ozonation disinfection system on four separate occasions. In general, the results indicated a decrease in total coliform bacteria due to filtration and ozone disinfection, as shown in Figures 3 (first pass results) and 4 (second pass results). However, traces of total coliform less than $10 \mathrm{MPN} / 100 \mathrm{~mL}$ were still present at the end of the second pass.

The coliform bacteria concentration decreased from an average of approximately 750 MPN/100 mL at the raw water tank to below the detection limit at most sample ports after ozone was introduced to the system on the first pass. An increase in coliform bacteria concentration between the final sample of the first pass and the first sample of the second pass was noted. As previously stated, the system was not chlorine-decontaminated prior to use; the noted increase in concentration after the first treatment pass could be caused by bacteria living on the sides of the clean water tank or within the piping. E. coli levels were below the detection limit in the raw water source, so it was not possible to evaluate treatment of $E$. coli within the system.

The water quality results show the effectiveness of the filters and ozonator in removing bacteria and disinfecting water. The method used to test for coliform bacteria had a detection limit of $10 \mathrm{MPN} / 100 \mathrm{~mL}$, so we could not show compliance with the EPA total coliform rule of a MCL level of zero after the second pass. However, considering the current drinking water 
conditions in communities where these systems are being installed, reducing the number of total coliform bacteria from over $1000 \mathrm{MPN} / 100 \mathrm{~mL}$ to less than $10 \mathrm{MPN} / 100 \mathrm{~mL}$ can be considered an improvement.

Flow rate measurements were recorded during each pass of the sampling process. The average flow rates were 5 gallons per minute (gpm) on the first pass and $10 \mathrm{gpm}$ on the second pass. The flow rate is lower on the first pass through the system because the water passes through the filters, adding head against the pump and decreasing the flow rate.

Water pressures upstream of the 5- $\mu \mathrm{m}$ filter (component 4 in Figure 1) were recorded. On the first pass, average pressures were 42 pounds per square inch - gauge (psig).

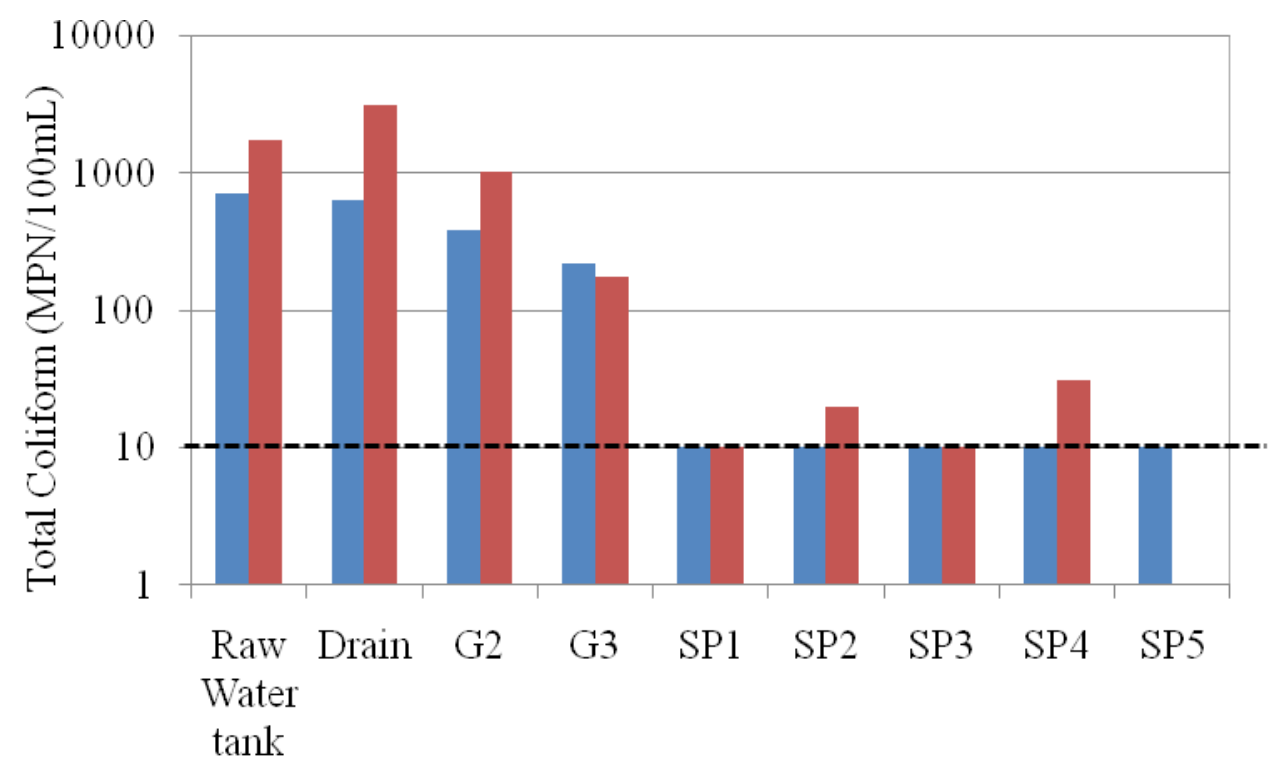

- Trial 1 - Trial 2 ---- Dashed line represents detection limit

\section{FIGURE 3}

The RESULTS OF TOTAL COLIFORM BACTERIA MEASUREMENTS IN WATER DURING THE FIRST PASS THROUGH THE OZONE DISINFECTION SYSTEM. 


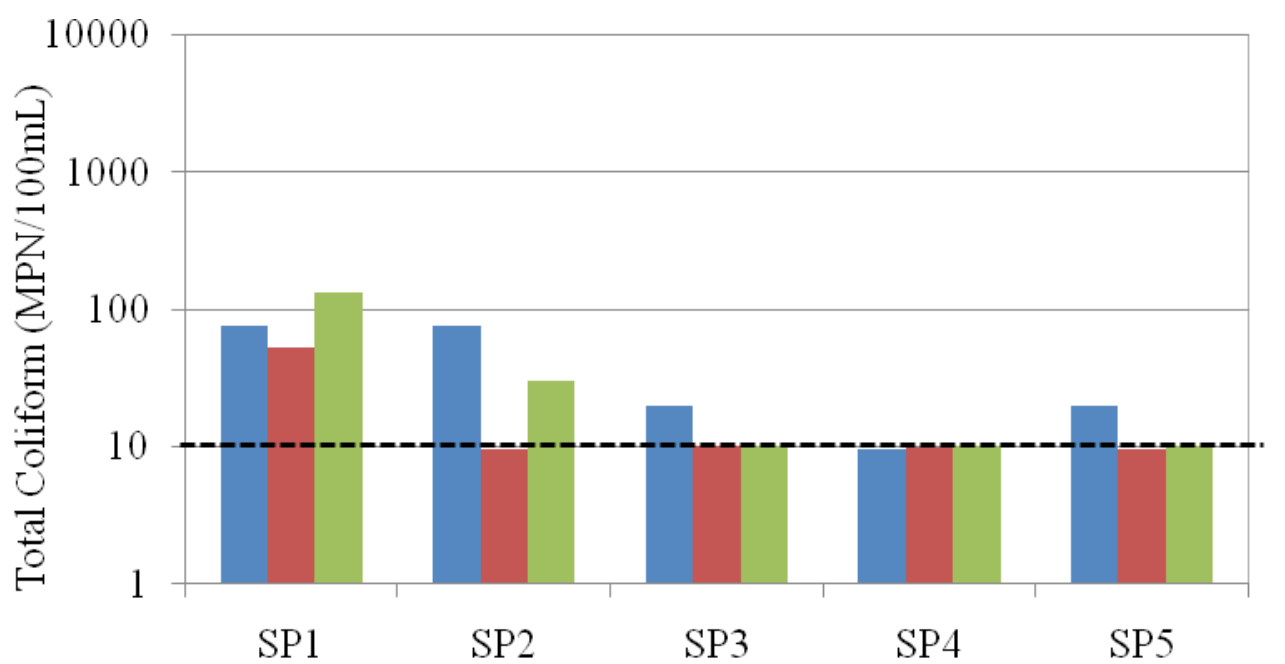

- Trial 1 - Trial 2 - Trial 3 ---- Dashed line represents detection limit

\section{FIGURE 4}

THE RESULTS OF TOTAL COLIFORM BACTERIA MEASUREMENTS IN WATER DURING THE SECOND PASS THROUGH THE OZONE DISINFECTION SYSTEM.

The average measured ozone concentration was $0.06 \mathrm{mg} / \mathrm{L}$ on the first pass and 0.09 $\mathrm{mg} / \mathrm{L}$ on the second pass. The concentration of DO measured in the first pass increased from upstream of the venturi to the end of the plug flow reactor. On the second pass, DO increased from approximately $11 \mathrm{mg} / \mathrm{L}$ in SP1 to $13 \mathrm{mg} / \mathrm{L}$ in SP5. ORP measurements on the first pass averaged about $250 \mathrm{mV}$. ORP measurements increased between each sample port along the plug flow reactor as well as in each consecutive trial of the second pass. The bar chart from the first pass clearly shows an increase in ORP of the water between sample port G3 and sample port SP1. This is likely due to ozone entering the system (Figure 5). The average ORP during the second pass increased from about $375 \mathrm{mV}$ in SP1 to $400 \mathrm{mV}$ in SP5 (Figure 6). 


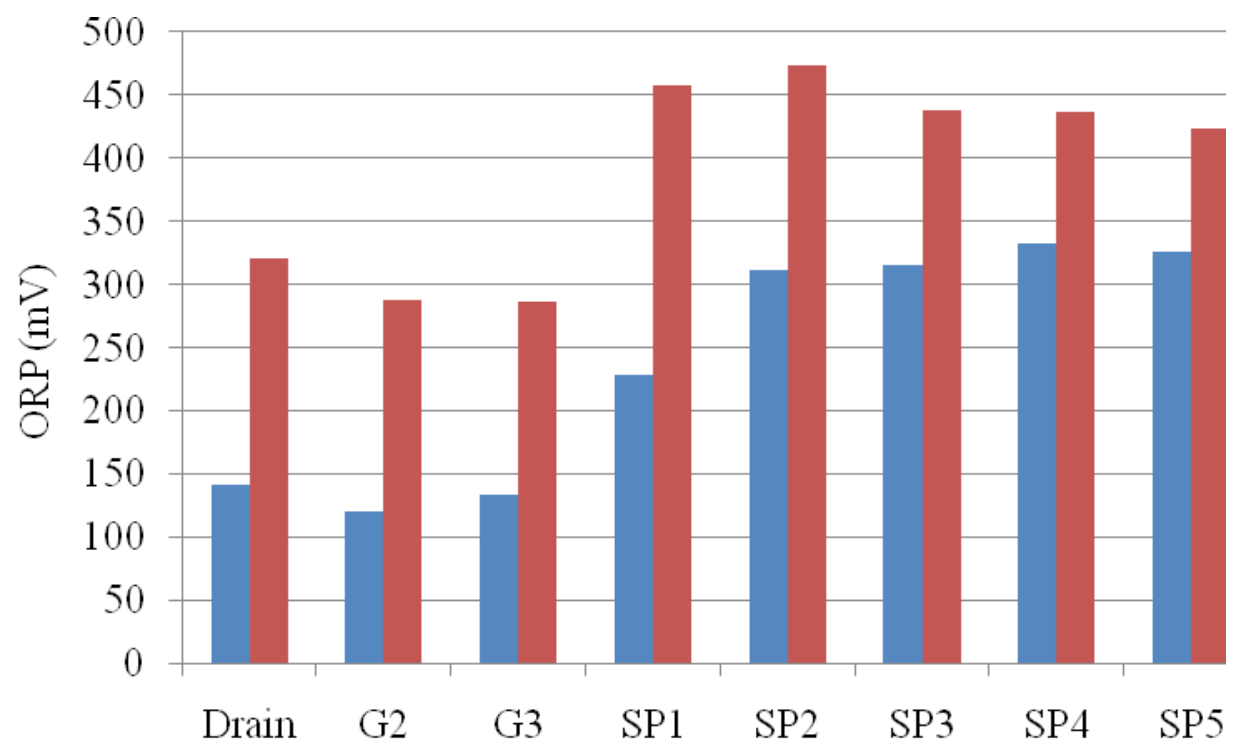

- Trial 1 - Trial 2

\section{FIGURE 5}

RESULTS OF ORP MEASUREMENTS IN THE WATER DURING THE FIRST PASS THROUGH THE OZONE DISINFECTION SYSTEM.

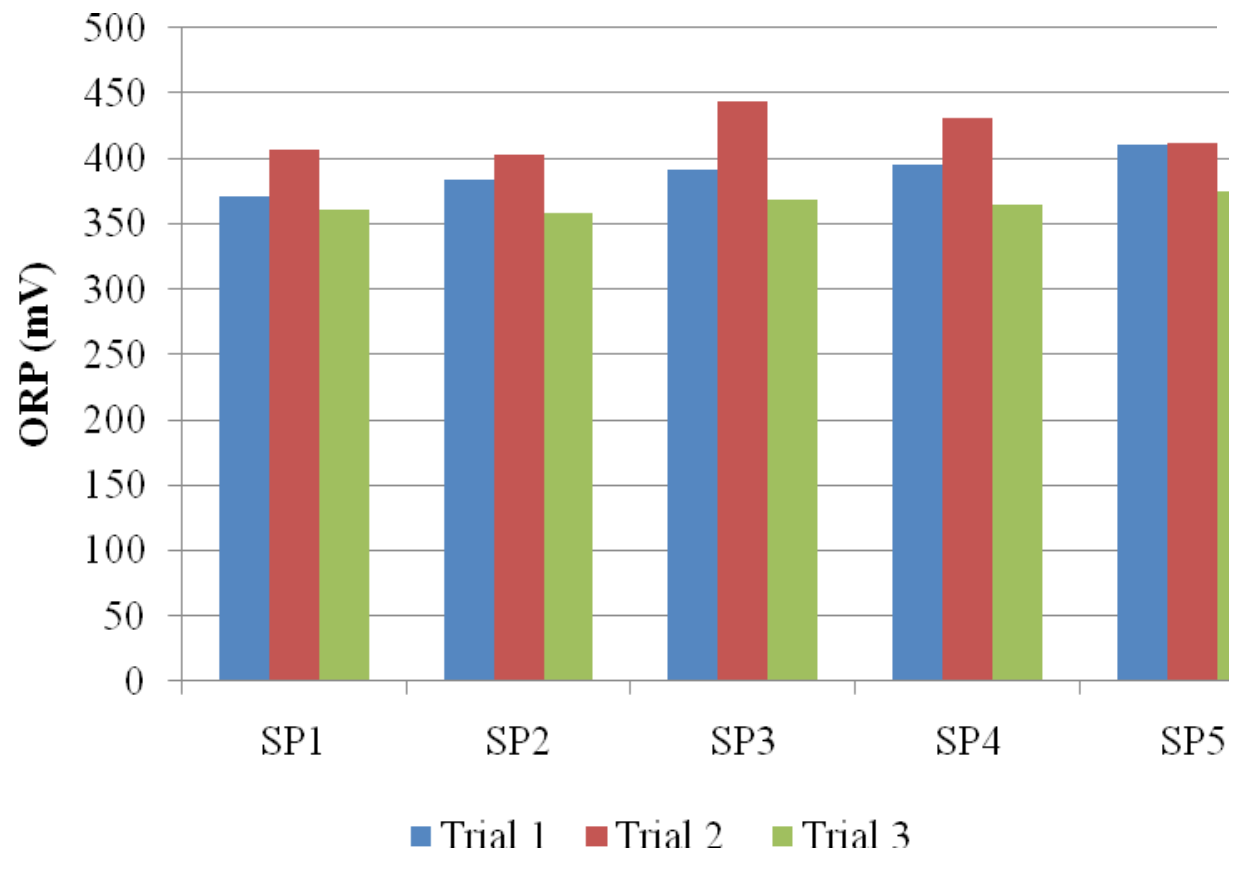

FIGURE 6

RESULTS OF ORP MEASUREMENTS IN THE WATER DURING THE SECOND PASS THROUGH THE OZONE DISINFECTION SYSTEM. 
Plotting the total coliform concentration versus ORP results from all experiments revealed a strong and significant inverse correlation (Spearman's rank correlation $=-0.73, p<$ 0.01 ), as shown in Figure 7. In other words, as the ORP of the water increases, total coliform concentration decreases.

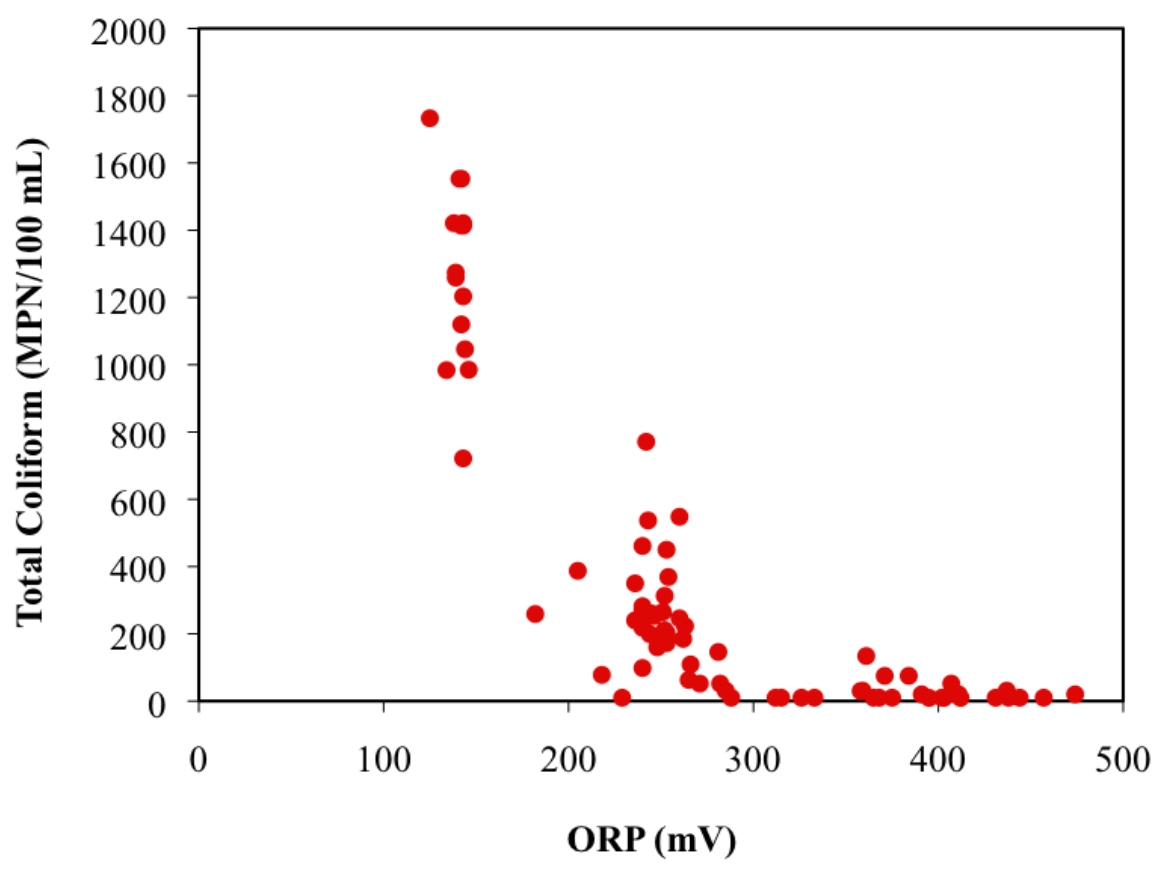

FIGURE 7

RESULTS OF WATER QUALITY DATA FROM ALL EXPERIMENTS REVEAL AN INVERSE CORRELATION BETWEEN ORP AND TOTAL COLIFORM CONCENTRATION.

\section{Development of a Chlorination Analytical Model}

The chlorination analytical model is shown as a table, with example values, in Figure 8. This table can be used to quickly estimate the concentration of chlorine in a volume of water, given the amount of bleach added and the percent available chlorine in that bleach, to determine if it falls in an acceptable range for its intended use. For example, if the operator needs to know if a tank of water contains enough chlorine for residual disinfection, he can use this table to estimate the chlorine concentration. If 1 tablespoon (or $14.79 \mathrm{~mL}$ ) of bleach with $5.7 \%$ available chlorine were added to $1100 \mathrm{~L}$ of water (a typical storage tank volume), the resulting chlorine concentration in the water would be $0.83 \mathrm{mg} / \mathrm{L}$. This concentration exceeds the acceptable range for residual disinfection, and the operator would have to choose a smaller volume of bleach. 


\begin{tabular}{|l|l|}
\hline Batch of water used: & 1100 Liters \\
\hline
\end{tabular}

\begin{tabular}{|c|c|c|c|c|c|c|c|}
\cline { 3 - 8 } \multicolumn{2}{c|}{} & \multicolumn{5}{c|}{ Concentrations of Chlorine (ppm or mg/L) } \\
\hline \multicolumn{3}{|c|}{ Volume of bleach added } & \multicolumn{4}{c|}{ Bleach characteristic. \% available chlorine } \\
\hline (mL) & (ounces) & Tablespoons & $4.50 \%$ & $5.00 \%$ & $5.70 \%$ & $6.00 \%$ & $6.50 \%$ \\
\hline 3.70 & $1 / 8$ & $1 / 4$ & 0.16 & 0.18 & 0.21 & 0.22 & 0.24 \\
\hline 4.93 & $1 / 6$ & $1 / 3$ & 0.22 & 0.24 & 0.28 & 0.29 & 0.32 \\
\hline 7.39 & $1 / 4$ & $1 / 2$ & 0.33 & 0.37 & 0.42 & 0.44 & 0.48 \\
\hline $\begin{array}{c}14.7 \\
9\end{array}$ & $1 / 2$ & & 0.66 & 0.73 & & & \\
\hline $\begin{array}{c}29.5 \\
7\end{array}$ & 1 & & 1.32 & 1.46 & 1.67 & 1.76 & 1.90 \\
\hline $\begin{array}{c}44.3 \\
6\end{array}$ & $11 / 2$ & 3 & 1.97 & 2.19 & 2.50 & 2.63 & 2.85 \\
\hline $\begin{array}{c}59.1 \\
5\end{array}$ & 2 & 4 & 2.63 & 2.92 & 3.33 & 3.51 & 3.80 \\
\hline
\end{tabular}

FIGURE 8

THE CHLORINE DISINFECTION TABLE WAS CREATED TO ALLOW OPERATORS TO ESTIMATE THE CONCENTRATION OF CHLORINE IN A VOLUME OF WATER, GIVEN THE AMOUNT OF BLEACH ADDED AND THE PERCENT AVAILABLE CHLORINE IN THE BLEACH. THE INPUT PARAMETERS CAN BE CHANGED TO FIT THE NEEDS OF THE OPERATOR.

The accuracy of the results was verified through the use of chlorine test strips (commonly available among swimming pool supplies in hardware stores), which change color in response to the presence of chlorine in the solution. The concentration of chlorine in the water is estimated by comparing the color of the test strips to a set of comparators with assigned chlorine concentrations. The chlorine concentration was also checked using the colorimetric method, where vials containing the solution and color reagents are tested by a photometer, such as the CHEMetrics model used in this class.

\section{Conclusions}

Students discussed and interpreted results in class meetings and expressed their newfound social insights about the LWW clean water systems through reflection assignments.

\section{Ozone Disinfection System}

Overall, the water treatment system significantly decreased the concentrations of total coliform bacteria, rendering the water safer to drink.

The decrease in total coliform observed downstream of the two microfilters indicated the effectiveness of the filtration system in removing microorganisms. Ozone was difficult to measure accurately because of its instability. However, it was evident that ozone disinfected water because of the decrease in total coliform along the plug flow reactor. Traces of total coliform less than $10 \mathrm{MPN} / 100 \mathrm{~mL}$ were still present at the end of the second pass. This could be attributed to the fact that the system was not chlorine-disinfected before experimentation, 
simulating a worst-case scenario. Through conversations with LWW members, students learned of instances when system operators in developing regions removed the microfilters to yield greater water flow rates or discontinued the practice of periodically disinfecting the system with chlorine. Through the reflection essays, many students expressed that proper communication between mission groups trained by LWW and in-country system operators was necessary to emphasize the importance of the microfilters and of periodically disinfecting the system. Students were satisfied in the knowledge that the water quality measurements that they conducted may be used in demonstrating to system operators the importance of microfiltration and chlorine disinfection.

Another important operation activity discovered by the students was the recording of the pressure reading from the pressure gauges. During one of the treatment system testing events, the pressure upstream of a microfilter reached $48 \mathrm{psi}$, an increase from $42 \mathrm{psi}$. Students continued to run the system as usual but noticed that ORP measurements had decreased. Through a group discussion during the event, it was concluded that one of the filters was clogged, greatly decreasing the flow rate of water, and consequently decreasing the rate of ozone injected in the system through the venturi. Through reflection assignments, students noted the importance of recording and comparing pressure data on the system in order to detect filter clogging. Students also noted that these recording activities may be difficult for operators who may be illiterate. One student suggested that one way to help such an operator track pressure changes would be to mark directly on the pressure gauge an acceptable range of pressures. In this manner, when an operator sees the gauge pointer outside of the range, he or she would know to change out a filter.

Water flow rates were collected to calculate contact times of ozone and water through the plug flow reactor. The lower flow rate on the first pass permits a longer contact time between the ozone and the raw water, enabling greater deactivation of bacteria. A greater flow rate is permitted on the second pass since the water does not pass through the filters. As this is the second time the water has been treated with ozone, a shorter contact time is appropriate. On the other hand, the increased water flow rate in the second pass results in an increased ozone injection through the venturi. Theoretically, a " $C t$ " value can be calculated, where $C$ is the ozone concentration and $t$ is the contact time. Maximizing the $C t$ value, whether by increasing $C$ or $t$, would maximize disinfection. ${ }^{\text {ii }}$ However, the measured ozone concentrations were significantly lower than the expected values based on communications with the ozonator manufacturer. Ozone concentration measurements are considered highly unreliable because of the extremely unstable nature of this gas. Through this ozone measurement exercise, students learned that not all measurements are reliable, and that at times, other parameters may serve as surrogates for the wanted parameter. DO and ORP measurements then served as indicators of the presence of ozone. For example, DO concentrations in water increased when ozone was injected into the plug flow reactor, demonstrating that the added ozone was dissociating into oxygen. Also, DO was higher on the second pass than on the first pass, indicating that the elevated water flow rate allowed more ozone to be pulled through the venturi, adding more oxygen to the water. The increased ORP in the presence of ozone was also an expected result; as more ozone is injected into the water, the oxidation potential of the water should increase. The inverse correlation between total coliform and ORP (Figure 7) is representative of the oxidation of bacteria due to ozone; as more ozone enters the water (shown by higher ORP values), more bacteria is oxidized and killed (indicated by lower bacteria concentrations). When the ORP of the water exceeds approximately $300 \mathrm{mV}$, total coliform concentration is generally below $10 \mathrm{MPN} / 100 \mathrm{~mL}$. The finding that DO and ORP are good indicators of ozone led the students to suggest to LWW that 
mission groups should take DO or ORP measurement instruments to their community partners in order to measure evidence of ozone.

\section{Chlorination Analytical Model}

The chlorination table (Figure 8) developed can be used to quickly determine the concentration of chlorine needed in a certain volume of water, given the amount of bleach added, the volume of water involved, and the percent of available chlorine present in the bleach. This easy to use reference table provides operators with the recommended chlorine dosage for a variety of disinfection applications as well as for decontamination of system components.

This table is appropriate for use by the operating partner when the mission group can use the Excel file to customize the tank volume, bleach measurement methods, and the desired chlorine concentrations. Therefore, it is not expected that the operating partner have a computer and knowledge of spreadsheet software. The students provided LWW with the spreadsheet so that it can be distributed for mission groups to adjust them to their operating partners' situations. In addition, reflecting on the fact that operating partners may not own laboratory glassware, students developed the table to include measurements in units of cups and tablespoons. These more common utensils are more useful units of measurement of bleach volumes. Additionally, having learned that many populations dislike the taste of chlorine, students developed the table to also contain very small concentrations of residual chlorine that may be undetected by the palate. These concentrations of chlorine would be used in cases when it is necessary to provide a residual chlorine concentration in a tank or bottle.

Through this service learning experience students expressed in reflection assignments how their problem-solving skills had improved and how they were motivated to work as a team to solve problems that were real. In fact, the questions that the students answered through this experience had been posed directly to them by LWW representatives. Students' motivation to provide good answers was high because they realized the importance of providing clean drinking water to people. This course directly addressed a publication by Pearce ${ }^{\text {iv }}$ calling for students to solve problems through service learning by experimenting with appropriate and sustainable technology that could be used in developing nations.

\section{ACKnowledgements}

We thank the other seven Fall 2009 Service Learning students for contributing to the work that went into this paper: Nicholas Farney, Lorena Lica, Joseph Murphy, Aaron Pullen, Timothy Richardson, and Frank Roecker. We also thank the members of LWW who taught us the treatment system and provided ideas for collaboration: Wil Howie, Floyd Groves, Harlon Mills, David Parks, George Plouffe, Mark Tew, and Ralph Young. We thank the University of Mississippi Department of Civil Engineering for providing funds to purchase Clean Water Handbooks and water testing supplies.

\section{REFERENCES}


'The United Nations, The Millennium Development Goals Report 2008 (2008), 42.

iiRonald L. Droste, Theory and Practice of Water and Wastewater Treatment, (1997), 514-30.

iii Living Waters for the World, Clean Water Systems Handbook, Vol. 1 (2009).

vJoshua M. Pearce, "Service learning in engineering and science for sustainable development." International Journal for Service Learning in Engineering, Vol. 1 (2006), 1-4. 